\title{
Saúde mental e diferentes horários de trabalho para operadores de petróleo
}

\author{
Mental health and different work \\ shifts for oil industry workers
}

\author{
Silvânia da Cruz BARBOSA \\ Livia de Oliveira BORGES ${ }^{2}$
}

\section{Resumo}

Esta pesquisa identificou perfis de saúde mental em uma amostra de 144 operadores de petróleo engajados em diferentes horários de trabalho. Aplicaram-se os instrumentos: Questionário de Saúde Geral (versão reduzida de 12 itens), Escala de Autoestima, Escala de Afetos Positivos e Negativos e a escala de atributos valorativos do Inventário de Motivação e Significado do Trabalho. Os fatores empíricos foram usados como indicadores para medir cinco dimensões de saúde mental propostas no modelo ecológico de Peter Warr. Identificaram-se quatro perfis de saúde mental: Equilibrado, Ansioso, Oscilante e Satisfatório. Analisando a variância dos perfis por horário de trabalho (análise de conglomerados), observou-se que os operadores engajados no turno ininterrupto de revezamento e no regime de sobreaviso tendem a apresentar os perfis Equilibrado e Satisfatório, enquanto os que trabalham nos regimes administrativo e administrativo de campo, os perfis Ansioso e Oscilante.

Unitermos: Análises estatísticas. Bem-estar subjetivo. Jornada de trabalho. Saúde mental.

\begin{abstract}
This research identified mental health profiles in a sample of 144 oil ind ustry workers engaged in different work shifts. The following questionnaires were applied:General Health Questionnaire (reduced version consisting of 12 items), Self-Esteem Scale, Positive and Negative Affect Scale and the scale of value attributes in the Motivation Inventory and Meaning of Work. Empirical factors were used as indicators to measure five dimensions of mental health in accordance with Peter Warr's ecological model. Four profiles of mental health were identified: 1) Balanced, 2) Anxious, 3) Oscillating; and 4) Satisfactory. When the variation in profiles was analyzed per work shift (cluster analysis), it was observed that the oil industry workers engaged in continuous, rotating shifts and on standby shifts tend to present the balanced and satisfactory profiles, while those working in the areas of administration and field administration tend to present anxious and oscillating profiles.
\end{abstract}

Uniterms: Statistical analysis. Subjectivity. Work hours. Mental health.

O horário de trabalho tem potencial de estruturação do tempo e de organização da vida das pessoas, conforme a literatura especializada vem tratando
(Blanch, 1996; Blanch, Espuny, Gala \& Martín, 2003; Garrido, 2006; Jahoda, 1987; Kohn \& Schooler, 1983; Locke \& Taylor, 1990). Representa, então, uma das dimensões das condi-

$\boldsymbol{\nabla \nabla \nabla \nabla}$

1 Universidade Estadual da Paraíba, Centro de Ciências Biológicas e da Saúde, Departamento de Psicologia. R. das Baraúnas, 35, Universitário, 58429-500, Campina Grande, PB, Brasil. Correspondência para/Correspondence to: S.C. BARBOSA. E-mail: <silv.barbosa@gmail.com>.

2 Universidade Federal de Minas Gerais, Faculdade de Filosofias e Ciências Humanas, Departamento de Psicologia. Belo Horizonte, MG, Brasil.

Agradecimentos: à Coordenação de Aperfeiçoamento de Pessoal de Nível Superior e ao Conselho Nacional de Desenvolvimento Científico e Tecnológico, ao Programa Integrado de Pós-Graduação em Psicologia Social da Universidade Federal do Rio Grande do Norte e a Universidade Estadual da Paraíba. 
ções de trabalho que mais geram impacto na vida e bem-estar psicológico dos trabalhadores. Segundo Garrido (2006), quando um trabalhador perde controle sobre a organização do tempo e passa a conviver com mudanças consecutivas de turno, com jornadas excessivamente longas e rápidas rotações dos dias de descanso, sua saúde psíquica pode estar em risco.

Tendo em vista a frequência, cada vez maior, de horários noturnos e de turnos alternados de trabalho na atual sociedade 24 horas e, diante dos possíveis riscos que eles podem causar, cresce o interesse no campo da saúde mental e trabalho em estudar como tais horários afetam o trabalhador. Partilhando desse interesse, a presente pesquisa foi desenvolvida com o objetivo de identificar os perfis de saúde mental dos operadores de petróleo da Petrobrás atuantes na Bacia Potiguar, diferenciados por horário de trabalho.

Como dentro desse campo de conhecimento existem muitas abordagens sobre o que seja saúde mental, a seção seguinte será dedicada a esclarecer o conceito que fundamentou a presente pesquisa.

\section{O conceito de saúde mental segundo o modelo ecológico de Warr}

Até meados do século passado predominou na mentalidade científica uma concepção de saúde como se fosse ausência de doença. Nesse ponto de vista, as doenças tinham causas biológicas e pouca relação com os problemas psicológicos e sociais, o que conduziu muitas pesquisas em Psicologia Organizacional e do Trabalho a focalizarem quase que exclusivamente aspectos negativos da saúde (enfermidades).

A partir de 1948, quando a Organização Mundial de Saúde (OMS) definiu a saúde como "um estado de completo bem-estarfísico, mental e social, enão somente como ausência de enfermidades" (World Health Organization - WHO, 1948), a saúde passou, gradualmente, a ser vista de forma menos reducionista e mais integral. Apesar das críticas existentes atualmente sobre tal conceito, como sua baixa utilidade para diferenciar qualidades e intensidades de saúde, e das tendências atuais da própria WHO para atualizá-lo com a intenção de torná-lo mais mensurável (Benavides, García \& Ruiz-Frutos, 2004), tal conceito foi um marco no estabelecimento da tendência nas pesquisas de identificar também os aspectos positivos de saúde.
O conceito proposto pela WHO atende à complexidade do construto, sendo congruente com a ideia de que a enfermidade física é apenas uma das manifestações do desequilíbrio orgânico, e de que se devem levar em conta os aspectos psicológicos e sociais para compreender a saúde. A partir de 1960, intensificaram-se os avanços científicos, sendo incorporados cada vez mais nas pesquisas os fatores não biológicos (como meio ambiente, aspectos sociodemográficos, condições de vida e fatores de experiência) para melhor entender os processos de saúde e doença.

Mesmo tendo percorrido um longo caminho evolutivo, o conceito de saúde ainda continua amplo, ambíguo e de difícil operacionalização, visto que é carregado dos valores sociais predominantes em cada tempo e lugar (Canguilhem, 1995; Ogden, 1999; Warr, 1987). Sendo produto de uma construção sócio-histórica, não há uma definição de saúde universalmente aceita e aplicável a todos os povos, épocas e culturas, podendo os processos psicológicos ser descritos e interpretados de diferentes formas, dependendo da perspectiva teórica de cada autor.

Conforme o enfoque adotado, a saúde pode ser vista, num sentido clínico, como ausência de sintomas de mal-estar. Pode, também, ser vista como um estado de bem-estar psicológico e social de um indivíduo ou grupo de indivíduos num dado contexto sociocultural, indicando sentimentos positivos (prazer, satisfação, comodidade) ou negativos (ansiedade, depressão, insatisfação). Por sua vez, os componentes e processos da saúde podem ser tomados como variáveis indicadoras de condutas de enfrentamento a situações continuamente desgastantes, ou podem ser tomados como variáveis preditoras de uma vida saudável, resultante de práticas preventivas contra doenças.

No campo de estudo em saúde mental e trabalho, no qual a presente pesquisa se insere, existem diferentes formas de abordar a saúde, mas dadas as especificidades de suas bases epistemológicas, todas elas compreendem a problemática da saúde no trabalho a partir de fatores antecedentes e das consequências para o indivíduo e para seu contexto laboral. As principais diferenças encontradas nessas abordagens dizem respeito à definição dos indicadores que podem focalizar aspectos de saúde, da doença ou do processo saúde/ doença, abrangendo indicadores de bem-estar, mal-estar 
ou a integração de ambas as dimensões (Mendes \& Cruz, 2004).

Dentro desse campo existem também diferentes modelos teóricos que permitem identificar fatores benéficos e/ou prejudiciais à saúde mental (psiquiátrico, psicanalítico, comportamentalista, cognitivo, psicossocial etc.), com conceitos, termos e estilos discrepantes entre si.

No modelo elaborado por Warr (1987), denominado ecológico, esses fatores são de caráter psicossocial e estão fortemente relacionados com o conteúdo do trabalho, com as condições de emprego, com a organização do trabalho e com as relações interpessoais que se estabelecem dentro do ambiente laboral. Nesse modelo, o conceito de saúde mental não é tomado no sentido psicopatológico, e sim, como sinônimo de bem-estar psicológico ou equilíbrio emocional. Portanto, estar mentalmente saudável significa manter um equilíbrio entre as experiências emocionais positivas e negativas, de modo que os sentimentos positivos prevaleçam sobre os negativos.

Associadas às divergências conceituais, há também divergências terminológicas. Assim, expressões como saúde mental, saúde psíquica, bem-estar psicológico, entre outras, são usadas sem suficiente e clara diferenciação conceitual. Aqui, emprega-se o termo saúde mental por ser aquele mais consolidado e o empregado no modelo ecológico, que se passa a descrever mais detidamente.

O modelo ecológico de Warr (1987) considera que a saúde mental é composta por cinco dimensões.

A primeira, denominada bem-estar afetivo, abrange vivências de estimulação e prazer que definem o quanto o indivíduo se sente bem internamente.

A segunda dimensão, denominada competência pessoal, define-se pela capacidade que o indivíduo tem para enfrentar as pressões do meio e solucionar problemas. Alerta-se, no entanto, que um baixo nível de competência nem sempre quer dizer que a saúde mental esteja deteriorada, pois, para que isso ocorra, é preciso que a primeira dimensão da saúde (bem-estar afetivo) esteja em um nível baixo.

A terceira dimensão, chamada autonomia, indica a capacidade da pessoa para atuar sobre as influências externas, fazendo valer suas próprias opiniões. Warr
(1987) explica que um bom nível de saúde mental requer certa independência para agir no ambiente e, também, que o indivíduo se sinta responsável pelo que faz.

A quarta dimensão, chamada aspiração, manifesta-se pelo grau de interesse e esforço desprendido para buscar novas oportunidades e atingir os próprios objetivos valorados. Para o autor, um nível moderado de motivação ou aspiração repercute positivamente na saúde mental; em contrapartida, um nível muito baixo origina apatia e um nível muito elevado, ansiedade crônica.

Por fim, a quinta dimensão, chamada funcionamento integrado, distingue-se das demais por considerar a pessoa em sua totalidade, supondo um equilíbrio entre as outras dimensões.

Segundo o modelo ecológico, se o indivíduo apresenta deficits em uma ou mais dessas dimensões psíquicas, sua saúde pode estar em risco, sendo que os níveis de alterações psíquicas (baixos, constantes, elevados) variam entre os indivíduos de acordo com seus atributos pessoais e com a forma como percebem o ambiente em que estão inseridos. Os atributos pessoais moderam o impacto do ambiente sobre a saúde, sendo tais atributos avaliados por meio das dimensões de saúde, já explicitadas, e por meio dos aspectos sociodemográficos.

\section{O ambiente e o horário de trabalho dos operadores de petróleo}

Para que se possa entender a influência do horário de trabalho na saúde mental, é imprescindível buscar informações sobre o contexto laboral dos trabalhadores. O caminho escolhido para buscar essas informações constituiu uma etapa preliminar desta pesquisa, durante a qual foram revisadas literaturas, realizadas visitas in loco às estações produtivas (terrestres e marítimas) e analisados documentos de uso público fornecidos pelo sindicato dos petroleiros e pela própria empresa. Esses procedimentos foram úteis para se obter uma visão mais apropriada da realidade laboral dos participantes, possibilitando descrever o ambiente e os regimes de trabalho em que eles atuam diariamente na Petrobrás, conforme descrito a seguir.

A Bacia Potiguar é uma Unidade de Negócio da Petrobrás, situada entre o Rio Grande do Norte e o Ceará 
(RN/CE), sendo que sua quase totalidade está no primeiro Estado, cobrindo um área de $48 \mathrm{mil} \mathrm{km}^{2}$ mar adentro e uma profundidade de 2 mil metros. Nessa Unidade de Negócio existem três células organizacionais produtoras de petróleo, denominadas Ativos Produção, com sedes geograficamente localizadas nos municípios de: 1) Alto do Rodrigues (ATP-ARG), responsável pela produção da área leste da bacia potiguar; 2) Mossoró (ATP-MO), responsável pela produção de óleo e gás da área oeste da bacia potiguar; e 3) Guamaré (ATP-M), responsável pela produção marítima, sendo formado por um polo industrial e plataformas marítimas.

Segundo Rocha (2005), a Bacia Potiguar ocupa atualmente a posição de maior produtora terrestre de petróleo do país, detendo quinze concessões exploratórias. Os poços em produção estão majoritariamente situados no município de Mossoró, sendo que a maior parte da produção advém de Canto do Amaro (CAM), hoje o principal campo produtivo terrestre do país, respondendo por 35,4\% de todo o petróleo terrestre produzido nacionalmente.

Os operadores de petróleo participantes da pesquisa exercem suas atividades diárias nas chamadas estações terrestres e/ou nas plataformas marítimas. Em visita às estações em terra, observou-se que elas ficam localizadas em áreas muito isoladas e distanciadas entre si, sendo ligadas por estreitas estradas de terra emaranhadas no meio da caatinga. Um operador sozinho é responsável por, no mínimo, três estações petrolíferas e, por isso, precisa estar constantemente se deslocando de uma estação a outra, chegando a percorrer longas distâncias durante toda a jornada de trabalho. Quanto às plataformas, são instalações complexas para exploração e produção do óleo. Operam distantes da costa marítima e, por isso, precisam funcionar com certo grau de autonomia. Essa localização implica um conjunto de ações coordenadas para manter os serviços de alimentação e alojamento da tripulação embarcada, bem como o fornecimento de água, energia, transportes (barcos e/ou helicópteros), serviços médicos e de comunicação, entre outros. Os operadores de petróleo podem exercer suas atividades em um dos seguintes horários de trabalho existentes na empresa:

1) Regime Administrativo (ADM): caracteriza-se 166 por um expediente corrido de 8 horas diárias, perfazendo um total de 40 horas semanais, com folga nos finais de semana. É aplicado aos que exercem serviços exclusivamente burocráticos.

2) Turno Ininterrupto de Revezamento (TIR): caracteriza-se por uma jornada diária de 12 horas e carga semanal de 33,6 horas. Nesse esquema, os grupos se revezam em turnos, cumprindo 14 dias de trabalho e 21 dias de folga. O revezamento funciona da seguinte forma: após sete dias de trabalho, os grupos têm sete dias de folga; em seguida ficam mais sete dias confinados e têm 14 dias de folga. Uma turma trabalha de $7 \mathrm{~h}$ a $19 \mathrm{~h}, \mathrm{e}$ outra de $19 \mathrm{~h}$ a $7 \mathrm{~h}$, sendo que aquela que trabalhou à noite, na semana seguinte trabalhará durante o dia. Esse horário se aplica aos que ficam confinados em terra ou, em alto mar (embarcados).

3) Regime Especial de Campo (REC): esse horário foi criado para atender a necessidades especiais da empresa (falta de empregados, licenças, férias etc.). Os empregados engajados nesse esquema também trabalham 12 horas diárias, com carga semanal de 33,6 horas, mas diferentemente do turno TIR, após uma semana de trabalho, folgam 12 dias. Esse horário é aplicado somente aos empregados que exercem atividades operacionais ou administrativas (não enquadradas como turno TIR) exercidas em locais confinados em áreas terrestres ou equipes sísmicas.

4) Regime de Sobreaviso: caracteriza-se por uma jornada diária de 12 horas, com 1,5 dia de folga para cada dia de trabalho. Nesse esquema, os operadores permanecem em estado de prontidão, podendo ser chamados a qualquer hora do dia ou da noite, inclusive em períodos de folga e momentos de descanso.

5) Regime Administrativo de Campo (ADM de Campo): horário semelhante ao do Regime Administrativo. A diferença é que, nesse esquema, trabalham operadores que se dividem entre o trabalho burocrático e de campo.

Por ocasião da pesquisa, esta última modalidade de horário ainda não havia sido oficializada, mas vinha sendo praticada desde 1993, regulada por circulares e norma interna. Os demais horários constavam no Acordo Coletivo de Trabalho (Petrobrás, 2005), sendo todos eles resultantes de negociações entre os empregados e a Companhia. 


\section{Método}

A pesquisa de campo seguiu um design transversal, definido por Bordalo (2006) como um tipo de estudo no qual fator e efeito são observados num dado momento histórico. Insere-se, também, dentro do que Gil (1987) classifica como pesquisa descritiva, que visa caracterizar uma dada população ou fenômeno explorando relações entre variáveis, sem manipulá-las; e ainda dentro do que Bruyne, Herman e Schoutheete (1977) classificam de pesquisa comparativa, a qual procura identificar semelhanças e diferenças entre grupos.

\section{Participantes}

Nos três Ativos Produção que cobrem a Bacia Potiguar trabalhavam 536 operadores de petróleo em horários diferenciados. A amostra foi não probabilística porque o critério de abordagem às pessoas deu-se por acessibilidade e aceitabilidade em participar do estudo. Foram recolhidos 146 questionários válidos, mas, após análises preliminares das características sociodemográficas, verificou-se que no Regime Especial de Campo (REC) existiam apenas dois sujeitos. Por ser um grupo muito pequeno e estatisticamente inviável, resolveu-se excluí-lo das análises principais e, a partir dessa exclusão a amostra totalizou 144 sujeitos, sendo 38 lotados em Alto do Rodrigues (27,0\%), 69 em Mossoró (48,0\%), 36 em Guamaré $(25,0 \%)$ e um (1,0\%) que não especificou o local de trabalho.

A amostra correspondeu, então, a 27,0\% da população com as seguintes características principais: a maioria era casada (66,0\%), do sexo masculino (96,0\%), com idade entre 19 e 56 anos (Média - M=39; Desvio-Padrão - DP=9,87) e com filhos (79,0\%). Quanto à escolaridade, 46,0\% completaram o ensino médio e 42,0\% possuíam nível superior. Todos ingressaram na Petrobrás por concurso público, variando quanto ao tempo de serviço na empresa de 1 a 28 anos ( $M=15,5 ; D P=9,36)$. A distribuição da amostra por regime de trabalho indica que a maioria (44,0\%) trabalhava no turno TIR, enquanto 34,0\% trabalhavam no regime ADM, 11,0\% no Sobreaviso, 10,0\% no ADM de Campo e 1,0\% não respondeu.

\section{Instrumentos}

Para avaliar as cinco dimensões da saúde mental segundo o modelo ecológico, foram utilizados o Questionário de Saúde Geral (QSG-12), o fator Autoestima Negativa da Escala de Autoestima, a Escala de Afetos Positivos e Negativos e dois fatores valorativos (1) Justiça no Trabalho e (2) Autoexpressão e Realização Pessoal do Inventário da Motivação e do Significado do Trabalho (IMST). A correspondência entre os fatores mensurados por esses questionários e as dimensões da saúde mental do modelo ecológico está sintetizada na Tabela 1.

O QSG-12 corresponde à versão resumida do Questionário de Saúde Geral criado por Goldberg (1972) para identificar transtornos mentais leves (não psicótico). É autoadministrável e, na maioria das pesquisas, é usado como instrumento unifatorial; no entanto, a pesquisa desenvolvida por Borges e Argolo (2002a; 2002b) aponta a adequação de mensurar dois fatores: 1) Deterioração da Autoeficácia, que diz respeito aos sentimentos de

Tabela 1. As cinco dimensões da saúde mental e seus indicadores. Natal (RN), 2008.

\begin{tabular}{|c|c|c|}
\hline $\begin{array}{l}\text { Dimensões da } \\
\text { saúde mental }\end{array}$ & Conceito das dimensões de saúde mental & Indicadores \\
\hline Bem-estar afetivo & $\begin{array}{l}\text { Diz respeito ao quanto o indivíduo se sente bem } \\
\text { internamente }\end{array}$ & $\begin{array}{l}\text { Os fatores: Depressão e Tensão Emocional do QSG-12, } \\
\text { Afetos Positivos e Afetos Negativos da escala de afetos, e } \\
\text { Autoestima Negativa da escala de autoestima }\end{array}$ \\
\hline Competência & $\begin{array}{l}\text { Capacidade para enfrentar pressões do meio e } \\
\text { solucionar problemas }\end{array}$ & O fator Deterioração da Autoeficácia do QSG-12 \\
\hline Autonomia & $\begin{array}{l}\text { Capacidade para atuar sobre as influências exter- } \\
\text { nas e determinar as próprias opiniões }\end{array}$ & \\
\hline Aspiração & $\begin{array}{l}\text { Grau de interesse e esforço desprendido para bus- } \\
\text { car oportunidades e atingir objetivos }\end{array}$ & $\begin{array}{l}\text { Os fatores da escala de atributos valorativos do IMST } \\
\text { (Justiça no Trabalho; Autoexpressão e Realização Pessoal) }\end{array}$ \\
\hline Funcionamento integrado & $\begin{array}{l}\text { Manifesta-se pela harmonia/equilíbrio entre todas } \\
\text { as outras dimensões }\end{array}$ & $\begin{array}{l}\text { Não foi usado nenhum indicador específico, e sim, o } \\
\text { conjunto dos indicadores anteriores }\end{array}$ \\
\hline
\end{tabular}


competência percebida pelo sujeito na realização das atividades; 2) Depressão e Tensão Emocional, que diz respeito aos sentimentos de tensão e esgotamento emocional. Os 12 itens que compõem o instrumento investigam se o sujeito experimentou recentemente algum sintoma de transtorno mental, devendo sua resposta ser dada em uma escala de quatro pontos que varia de 0 a 3 .

A Escala de Autoestima foi criada por Rosenberg (1965/1999) e conta com validação no Brasil realizada por Hutz (2002). Contém sete itens com respostas variando de '1' (concordo totalmente) a '4' (discordo totalmente), que permitem ao sujeito autoavaliar-se positiva ou negativamente.

A Escala de Afetos Positivos e Negativos foi elaborada por Diener e Emmons (1984) para avaliar a valência dos afetos. É composta por nove tipos de afeto, sendo quatro positivos (feliz, alegre, satisfeito e divertido) e cinco negativos (deprimido, preocupado, frustrado, raivoso e infeliz). Para equilibrar a quantidade de afetos, optou-se em seguir o procedimento usado nos estudos de Chaves (2003; 2007), em que se incluiu mais um afeto positivo: otimista. O objetivo da escala é avaliar quanto o sujeito tem experimentado cada uma das dez emoções dispostas no instrumento, em ordem numérica. A escala é formada por sete pontos que variam de ' 1 ', significando nada, a '7', significando extremamente. Segundo Chaves (2003), a comprovada adequação psicométrica dessa escala pode ser encontrada em pesquisas antecedentes.

O IMST foi elaborado por Borges e Alves-Filho (2001) para mensurar, no que diz respeito aos significados do trabalho, os atributos valorativos (o que o trabalho deve ser) e descritivos do trabalho (o que o trabalho é). Borges, Alves-Filho e Tamayo (2008) e Borges, Tamayo e Alves-Filho (2005) reavaliaram o referido inventário com amostras ocupacionais da cidade de Natal (RN), sendo que na última de suas pesquisas a amostra totalizou 555 pessoas, das quais 19,9\% são os petroleiros que participaram da presente pesquisa. A estrutura fatorial encontrada por esses autores identificou que os atributos valorativos são mensuráveis por quatro fatores: Justiça no Trabalho (Alfa=0,91), Autoexpressão e Realização Pessoal (Alfa=0,82), Sobrevivência Pessoal e Familiar (Alfa=0,78)

168 e Desgaste e Desumanização (Alfa=0,78).
Mesmo existindo estudos precedentes atestando a validade desses instrumentos, optou-se em repetir tais análises para confirmar se os parâmetros psicométricos das escalas estavam adequados à amostra. Aplicou-se, então, análise fatorial para verificar se os itens se agrupavam nos fatores previstos, e estimaram-se os coeficientes de Alfa de Cronbach ( $\alpha$ ) para verificar a consistência interna dos fatores. No QSG-12 foram identificados dois fatores: o primeiro com valor próprio (eigenvalue) de 5,72 e o segundo de 8,64, explicando, conjuntamente, $56,3 \%$ da variância total. Os fatores contam com itens com cargas fatoriais superiores a 0,30, correspondentes a Depressão e Tensão Emocional (Alfa =0,87) e Deterioração da Autoeficácia (Alfa =0,79).

Na escala de Autoestima foram identificados dois fatores com eigenvalues de 2,99 e 1,19, respectivamente, explicando, conjuntamente, 59,6\% da variância total. O instrumento ficou constituído por 6 itens com cargas fatoriais acima de 0,30 correspondentes aos fatores Autoestima Negativa (Alfa=0,77) e Autoestima Positiva (Alfa=0,61), sendo que apenas o primeiro fator foi usado na pesquisa, e o segundo foi descartado por apresentar baixa consistência interna. Na Escala de Afetos Positivos e Negativos identificaram-se dois fatores com eigenvalues de 6,07 e 1,14, respectivamente, ambos explicando $72,2 \%$ da variância total. O instrumento ficou constituído por 10 itens com cargas fatoriais superiores a 0,40, correspondentes aos fatores Afetos Negativos (Alfa $=0,91$ ) e Afetos Positivos (Alfa=0,87).

No IMST, o tamanho da amostra ( $\mathrm{N}=144)$ foi insuficiente para aplicar a análise fatorial. Contudo, considerou-se a variância dos escores nos fatores e a adequação para funcionar como indicadores da dimensão aspiração do modelo ecológico, concluindo que apenas os fatores (1) Justiça no Trabalho e (2) Autoexpressão e Realização Pessoal eram adequados.

Para caracterizar a amostra (idade, estado civil, escolaridade, tempo de serviço etc.) foi utilizada uma ficha sociodemográfica, sendo as respostas resumidas na seção que descreve os participantes da pesquisa.

\section{Procedimentos}

As respostas contidas nos questionários foram digitadas na forma de banco de dados do Statistical Packagefor the Social Sciencefor Windows (SPSS), por meio 
do qual foram realizadas as seguintes análises: estatísticas descritivas (média, desvio padrão e frequência) para caracterizar a amostra; análises fatoriais para verificar a validade dos instrumentos (referidas na seção anterior); estimativas dos escores em todos os fatores das escalas usadas, sendo que na escala de Autoestima inverteu-se o sentido da escala que passou a variar de "discordo totalmente"a"concordo totalmente"; análise de conglomerados (Cluster) para identificar os perfis de saúde mental da amostra; e, por fim, teste de Qui-quadrado para avaliar a interdependência entre a distribuição dos perfis e o regime de trabalho.

\section{Resultados e Discussão}

Conforme explicitado na Tabela 1, a saúde mental dos participantes da amostra foi avaliada considerando cinco dimensões do modelo ecológico, mensuradas por meio de sete fatores empíricos. Assim, a primeira dimensão (Bem-estar afetivo) foi avaliada pelos fatores Depressão e Tensão Emocional, Afetos Negativos, Afetos Positivos e Autoestima Negativa.

No QSG-12, quanto mais elevada a pontuação nos fatores, maiores os prejuízos à saúde mental. A média da amostra no fator Depressão e Tensão Emocional foi de 1,04 (Tabela 2), indicando que os participantes apresentaram tendência a reduzida depressão e tensão emocional, já que a escala variava de 0 a 3. No entanto, o desvio-padrão chamou atenção para a variação dos escores, visto que 50 participantes apresentaram escores entre 1 e 2, enquanto 12 participantes apresentaram escores superiores a 2. Portanto, 43\% dos participantes apresentaram sintomas depressivos e de esgotamento emocional.
Na escala de Afetos Positivos e Negativos, quanto maiores as pontuações atribuídas às emoções positivas, melhor a saúde mental (escores a partir de 5) e, quanto menores as pontuações atribuídas às emoções negativas (escores até 3), também melhor a saúde mental. A Tabela 2 aponta que a média no fator Afetos Negativos foi menor do que a média encontrada no fator Afetos Positivos (2,79 e 4,83, respectivamente), indicando que entre os participantes prevaleceram sentimentos positivos. Para identificar se existia diferença estatisticamente significativa entre os afetos positivos e negativos, aplicou-se o teste $t$. O resultado $(t=-11,1 ; p \leq 0,001)$ confirma que a amostra tendia a experimentar mais afetos positivos que negativos.

Na escala de Autoestima, quanto mais o indivíduo concorda com os enunciados positivos e quanto mais discorda dos enunciados negativos, melhor sua autoestima. A Tabela 2 mostrou que a média no fator Autoestima Negativa foi de 1,73, com desvio-padrão baixo, considerando que a escala é de 0 a 7 . Observou-se que 110 participantes apresentam escores inferiores ou iguais a 2,indicando que os operadores de petróleo tendem a apresentar baixa autoestima negativa.

Os resultados estatísticos apresentados revelam que a maioria da amostra tendeu a experimentar um bem-estar afetivo positivo. Em outras palavras, a dimensão de bem-estar afetivo encontrou-se resguardada para a maioria. No entanto, foi muito ampla a proporção de participantes com sintomas depressivos e de tensão emocional.

A segunda dimensão da saúde (Competência) e a terceira (Autonomia) foram avaliadas pelo fator Deterioração da Autoeficácia do QSG-12. Altos escores no referido fator indicam que o indivíduo não se percebe

Tabela 2. Média da distribuição e desvio-padrão nos fatores usados para medir as dimensões de saúde mental. Natal (RN), 2008.

\begin{tabular}{lllcc}
\hline Dimensões de saúde psíquica & Escalas & Fatores & Média & Desvio-padrão \\
\hline Bem-estar afetivo & QSG-12 & Depressão e tensão emocional & 1,04 & 0,61 \\
& Afetos Positivos e Negativos & Afetos negativos & 2,79 & 1,22 \\
& & Afetos positivos & 4,83 & 1,15 \\
& Autoestima & Autoestima negativa & 1,73 & 0,76 \\
Competência e autonomia & QSG-12 & Deterioração da autoeficácia & 0,54 & 0,59 \\
Aspiração & IMST & Justiça no trabalho & 3,0 & 0,66 \\
& & Autoexpressão e realização pessoal & 3,1 & 0,61 \\
\hline
\end{tabular}


realizando bem suas atividades profissionais. A média da amostra nesse fator foi de 0,54 (Tabela 2), indicando uma tendência de percepção de baixa dificuldade entre os operadores para executar as tarefas. O desvio-padrão, entretanto, não foi baixo $(\mathrm{DP}=0,68)$. Detendo-se mais detalhadamente na distribuição, observou-se que 116 participantes apresentaram escores inferiores ou iguais a 1, enquanto 25 participantes tiveram escores entre $1 \mathrm{e}$ 2, e apenas 3 participantes, escores superiores ou iguais a 2. Encontrar uma proporção de 19,4\% dos participantes $(n=28)$ com escores em faixa de risco ou elevados deve ser visto como um sinal de alerta. Em síntese, embora predominassem sentimentos positivos referentes às dimensões de Competência e Autonomia para a maioria, havia um grupo necessitando de atenção nessas dimensões.

Para avaliar a quarta dimensão da saúde (Aspiração), tomaram-se os escores atribuídos pelos participantes aos fatores valorativos do IMST: Justiça no Trabalho e Autoexpressão e Realização Pessoal. A Tabela 2 mostra que as médias encontradas estão muito próximas entre si, sendo de 3,1 para o fator Autoexpressão e Realização Pessoal, e de 3,0 para o fator Justiça no Trabalho, o que indica que os operadores desejam igualmente e de forma muito intensa esses dois aspectos de trabalho.

Segundo Warr (1987), níveis muito altos de aspiração não devem ser considerados a priori bons resultados, visto que podem estar gerando ansiedade nos indivíduos, seja porque eles não percebem êxito em seus esforços, seja porque suas expectativas estão acima do que é possível conseguir. Considerando que nesses resultados predominaram níveis elevados de aspiração e que na primeira dimensão da saúde (bem-estar afetivo) existem 43,0\% dos participantes mencionando sintomas depressivos e de tensão emocional, estimaram-se os coeficientes de correlação entre os escores nos fatores Justiça no Trabalho e Autoexpressão e Realização Pessoal com os escores no fator Depressão e Tensão Emocional. Encontraram-se respectivamente $r=-0,17(p \leq 0,05)$ e $r=-0,22(p \leq 0,01)$, indicando que os níveis de aspiração encontrados podem estar entre as causas de tensão, produzindo ansiedade nos participantes.

Como a quinta e última dimensão da saúde (Funcionamento integrado) manifesta-se pelo equilíbrio 170 entre as quatro dimensões antes referidas, não se usou nenhum indicador específico para avaliá-la, e sim, o conjunto dos escores obtidos nas demais dimensões por cada participante. Aplicou-se, então, a Análise de Conglomerados ao conjunto dos escores nos sete fatores indicadores da saúde psíquica, para melhor analisar como a saúde integral se manifestava na amostra. Essa técnica possibilita identificar como os participantes combinam os escores atribuídos aos vários indicadores do bem-estar psicológico. Em outras palavras, a técnica divide a amostra em subgrupos, combinando seus escores de modo a evidenciar diferenças significativas entre eles e, ao mesmo tempo, as semelhanças dentro do próprio grupo. Uma vezaplicada a Análise de Conglomerados, foram identificados quatro grupos com os seguintes perfis de bem-estar psicológico: 1) Bem-estar psicológico Equilibrado, 2) Bem-estar psicológico Ansioso, 3) Bem-estar psicológico Oscilante e, 4) Bem-estar psicológico Satisfatório (Tabela 3).

Conforme a Tabela 3, o primeiro perfil (Equilibrado) é compartilhado por 58 participantes, sendo esse o grupo mais numeroso e o que apresenta as maiores médias em Afetos Positivos e em Autoexpressão e Realização Pessoal; inclusive dentro do próprio grupo essas são também as duas maiores médias, seguidas de Justiça no Trabalho. Apresenta os menores escores em Deterioração da Autoeficácia, em Depressão e Tensão Emocional, em Afetos Negativos e em Autoestima Negativa. Provavelmente esse grupo experimenta certo grau de ansiedade na luta por realização profissional e por melhores condições de trabalho; contudo, tem elevados escores nos sentimentos positivos e baixos escores nos negativos, o que o classifica como um grupo que se apresenta com a saúde mental equilibrada.

O segundo perfil (Ansioso) é compartilhado por 23 participantes, com as maiores médias em Afetos Negativos em comparação aos outros grupos. Dentro do grupo, as médias em Afetos Negativos e em Afetos Positivos são as mais altas e, como estão próximas, denota que existe certa oscilação e/ou ambiguidade entre esses dois tipos de sentimentos, sendo os negativos mais prevalentes. Também pontua alto em Autoexpressão e Realização Pessoal e em Justiça no Trabalho, e destaca-se por ter a maior média em Depressão e Tensão Emocional, o que o classifica como o grupo que, provavelmente, venha experimentando mais ansiedade. 
Tabela 3. Combinação dos escores nos diferentes indicadores do bem-estar psicológico ( $n=143)$. Natal (RN), 2008.

\begin{tabular}{lcccc}
\hline \multirow{2}{*}{ Indicadores do bem-estar psicológico } & \multicolumn{3}{c}{ Perfis de saúde mental } \\
\cline { 2 - 4 } & Equilibrado & Ansioso & Oscilante & Satisfatório \\
\hline Depressão e tensão emocional & 0,64 & 1,89 & 1,48 & 0,92 \\
Deterioração da autoeficácia & 0,22 & 1,00 & 1,23 & 0,40 \\
Afetos negativos & 1,90 & 4,75 & 3,61 & 2,61 \\
Afetos positivos & 5,83 & 3,20 & 4,26 & 4,58 \\
Autoestima negativa & 1,48 & 1,88 & 2,79 & 1,52 \\
Justiça no trabalho & 3,05 & 3,10 & 2,10 & 3,15 \\
Autoexpressão e realização pessoal & 3,30 & 3,12 & 18 & 44 \\
\hline Participantes $(n)$ & 58 & 23 & & 3,23 \\
\hline
\end{tabular}

Nota: A aplicação da análise de Cluster abrange o desenvolvimento de ANOVA que indicou que todas as variáveis consideradas são capazes de diferenciar significativamente os grupos $(p \leq 0,001)$.

O terceiro perfil (Oscilante) agrupa 18 participantes com pontuações altas e aproximadas em Afetos Positivos e em Afetos Negativos, o que denota oscilação e/ou ambiguidade entre esses dois sentimentos, sendo que, diferentemente do segundo grupo, os sentimentos positivos são levemente prevalentes. Também se destaca como o grupo que pontua mais alto em Deterioração da Autoeficácia e em Autoestima Negativa e tem a segunda maior média em Depressão e Tensão Emocional. Provavelmente, os participantes com esse perfil são os que mais experimentam dificuldades em realizar as atividades e tendem a se autoavaliar mais negativamente.

O quarto perfil (Satisfatório) agrupa 44 participantes com altas pontuações em Afetos Positivos e em Justiça no Trabalho. Em Autoexpressão e Realização Pessoal tem médias muito próximas aos dois primeiros grupos. Esse grupo, semelhante ao primeiro, experimenta tensão, porém em doses aceitáveis que não comprometem a saúde mental.

Observou-se nesses resultados que Afetos Positivos foi o indicador que mais se destacou favoravelmente em todos os grupos e que, embora o fator Depressão eTensão Emocional não tenha pontuado alto, a ansiedade se mostrou evidente nos grupos, sobretudo quando se leva em conta as altas médias para os indicadores que mediram a dimensão aspiração. Em síntese, o funcionamento integrado dos operadores de petróleo encontra-se preservado para a maioria $(71,3 \%)$, mas a soma dos participantes com perfis Ansioso e Oscilante revela quase um terço da amostra $(28,7 \%)$ com a saúde mental desgastada, o que deve servir como alerta para que medidas recuperativas do equilíbrio emocional possam ser tomadas.

Comparando os grupos segundo os perfis de saúde (conglomerados) por características sociodemográficas, encontraram-se diferenças significativas nas médias de tempo de serviço $(F=8,18 ; p \leq 0,001)$ e idade $(F=4,99 ; p \leq 0,01)$, indicando que os participantes com mais idade e tempo de serviço tendem a apresentar perfil Equilibrado ou Satisfatório (mais bem-estar), enquanto os participantes com menos idade e tempo de serviço tendem a apresentar perfis Ansioso ou Oscilante (menos bem-estar), conforme se vê na Tabela 4.

Como as atividades dos operadores de petróleo são complexas e altamente arriscadas, é possível que os fatores idade e tempo de serviço estejam sendo traduzidos como acúmulo de experiência profissional. Assim, para eles, quanto mais experiência adquirida, mais conforto psicológico para enfrentar a complexidade e os riscos diários que envolvem a tarefa.

\section{Os horários de trabalho e a saúde mental dos operadores de petróleo}

Para analisar a variabilidade dos perfis de saúde mental da amostra (clusters) por horário de trabalho, elaborou-se uma tabela de dupla entrada e aplicou-se o teste de Qui-quadrado. O resultado $\left[\chi^{2}(9,142)=20,17\right.$; $p \leq 0,02]$ rejeita a independência entre as duas variáveis. Conforme se vê na Tabela 5, as pessoas engajadas nos regimes TIR e Sobreaviso tendem a apresentar perfis de saúde mental Equilibrado e Satisfatório, enquanto as que trabalham nos regimes ADM de Campo e ADM tendem a apresentar perfis Ansioso e Oscilante. 
Tabela 4. Síntese geral dos perfis do bem-estar psicológico e características sociodemográficas. Natal (RN), 2008.

\begin{tabular}{|c|c|c|}
\hline \multirow{2}{*}{ Perfis do bem-estar psicológico } & \multicolumn{2}{|c|}{ Variáveis contínuas } \\
\hline & Tempo/serviço & Idade \\
\hline $\begin{array}{l}\text { 1) Equilibrado: Apresenta as maiores médias em Afetos Positivos e em Autoexpressão e Realização Pessoal, } \\
\text { e as menores médias em Deterioração da Autoeficácia, em Depressão e Tensão Emocional, em Afetos } \\
\text { Negativos e em Autoestima Negativa. Tem altos escores nos sentimentos positivos e baixos escores nos } \\
\text { negativos. Concentra operadores com mais idade e mais tempo de serviço na empresa }\end{array}$ & 18,6 & 42,4 \\
\hline $\begin{array}{l}\text { 2) Ansioso: Apresenta média alta e aproximada em Afetos Negativos e Positivos, sendo os sentimentos } \\
\text { negativos mais prevalentes. Também apresenta média alta em Autoexpressão e Realização Pessoal, em } \\
\text { Justiça no Trabalho e em Depressão e Tensão Emocional. Concentra os operadores com menos idade } \\
\text { e menos tempo de serviço }\end{array}$ & 8,2 & 33,5 \\
\hline $\begin{array}{l}\text { 3) Oscilante: Apresenta pontuações altas e aproximadas em Afetos Positivos e Negativos, sendo os } \\
\text { positivos ligeiramente prevalentes. Apresenta maior pontuação em Deterioração da Autoeficácia e em } \\
\text { Autoestima Negativa e tem a segunda maior média em Depressão e Tensão Emocional. Concentra os } \\
\text { operadores com a terceira maior média de idade e de tempo de serviço }\end{array}$ & 12,4 & 37,9 \\
\hline $\begin{array}{l}\text { 4) Satisfatório: Apresenta altas pontuações em Afetos Positivos, em Justiça no Trabalho e em Autoexpressão } \\
\text { e Realização Pessoal. Tem a segunda maior média de idade e de tempo de serviço }\end{array}$ & 16,5 & 39,3 \\
\hline Teste aplicado: Anova & $\mathrm{F}=8,18 ; p \leq 0,001$ & 4,$99 ; p \leq 0,01$ \\
\hline
\end{tabular}

Tabela 5. Combinação dos clusters nos diferentes regimes de trabalho ( $n=142)$. Natal (RN), 2008.

\begin{tabular}{|c|c|c|c|c|c|}
\hline \multirow{2}{*}{ Perfis de bem-estar psicológico } & \multicolumn{5}{|c|}{ Regimes de trabalho } \\
\hline & ADM & Sobreaviso & $\mathrm{TIR}$ & ADM de Campo & Total \\
\hline \multirow[t]{2}{*}{1 - Equilibrado } & 16 & 6 & 34 & 2 & 58 \\
\hline & 32,7 & 40,0 & 54,0 & 13,3 & 40,8 \\
\hline \multirow[t]{2}{*}{2 - Ansioso } & 12 & 1 & 4 & 5 & 22 \\
\hline & 24,5 & 6,7 & 6,3 & 33,3 & 15,5 \\
\hline \multirow[t]{2}{*}{3 - Oscilante } & 7 & 2 & 5 & 4 & 18 \\
\hline & 14,3 & 13,3 & 7,9 & 26,7 & 12,7 \\
\hline \multirow[t]{2}{*}{4 - Satisfatório } & 14 & 6 & 20 & 4 & 44 \\
\hline & 28,6 & 40,0 & 31,7 & 26,7 & 31,0 \\
\hline Participantes (n) & 49 & 15 & 63 & 15 & 142 \\
\hline
\end{tabular}

A aplicação da análise de Cluster abrange o desenvolvimento de ANOVA que indicou que todas as variáveis consideradas são capazes de diferenciar significativamente os grupos $(p \leq 0,001)$.

ADM: regimes administrativo; TIR: turno ininterrupto de revezamento.

Considerando todos os resultados descritos, foi possível examinar quais horários de trabalho estão mais associados a efeitos mais positivos e/ou negativos na saúde mental da amostra. As análises revelaram, então, que os operadores engajados no ADM de Campo são mais tensos, mais negativos e sentem mais dificuldades para exercer as atividades. Os de Sobreaviso e ADM apresentam estabilidade emocional, experimentam sentimentos positivos e não veem dificuldades em fazer as tarefas. Os de turno TIR destacam-se como os mais tranquilos, mais positivos e mais autônomos frente às tarefas. As análises também indicam que o horário ADM de Campo se destacou como o mais nocivo à saúde mental, e os turnos TIR e de Sobreaviso como os horários mais associados a efeitos positivos.

Pelos resultados obtidos e pelas lacunas deixadas no presente estudo, seria recomendável a realização de pesquisas mais detalhadas sobre a influência do horário de trabalho no bem-estar psicológico dos trabalhadores em seus aspectos epidemiológicos, e, também, que se ampliassem os indicadores como cultura e valores organizacionais, significado e centralidade do trabalho e satisfação no trabalho. Outra linha de estudo muito adequada seria aprofundar a análise do ambiente 
laboral (aqui pouco explorado) e suas repercussões nas relações familiares e no lazer, dado que em muitos casos a dificuldade de conciliar o horário de trabalho com a vida extralaboral decorre das formas de gestão organizacional e das condições de trabalho.

\section{Referências}

Benavides, F. G., García, A. M., \& Ruiz-Frutos, C. (2004). La salud y sus determinantes. In F. G. Benavides, C. Ruiz-Frutos \& A. M. García (Orgs.), Salud laboral: conceptos y técnicas para la prevención de riesgos laborales (pp.3-16). Barcelona: Masson.

Blanch, J. M. (1996). Psicología social del trabajo. In J. L. Alvaro, A. Garrido \& J. R. Torregrosa (Orgs.), Psicología social aplicada (pp.85-120). Madrid: McGraw-Hill Interamericana de España.

Blanch, J. M., Espuny, M. J., Gala, C., \& Martín, A. (2003). Teoría de las relaciones laborales: fundamentos. Barcelona: Editorial UOC.

Bordalo, A. A. (2006). Estudo transversal e/ou longitudinal. Revista Paranaense de Psicologia, 20 (4), 5. Recuperado em 2, 2009, disponível em <http://scielo.iec.pa.gov.br/pdf/ $\mathrm{rpm} / \mathrm{v} 20 \mathrm{n} 4 / \mathrm{v} 20 \mathrm{n} 4 \mathrm{a} 01 . \mathrm{pdf}>$.

Borges, L. O., \& Argolo, J. C. T. (2002a). Estratégias organizacionais na promoção da saúde mental do indivíduo podem ser eficazes? In G. Jacques \& W. Codo (Orgs.), Saúde mental e trabalho: leituras (pp.271-275). Petrópolis: Vozes.

Borges, L. O., \& Argolo, J. C. T. (2002b). Adaptação e validação de uma escala de bem-estar psicológico para uso em estudos ocupacionais. Avaliação Psicológica, 1 (1), 17-27.

Borges, L. O., \& Alves-Filho, A. (2001). A mensuração da motivação e do significado do trabalho. Estudos de Psicologia, 6 (2), 177-194.

Borges, L. O., Alves-Filho, A., \& Tamayo, A. (2008). Motivação e significado do trabalho. In M. M. M. Siqueira (Org.), Medidas do comportamento organizacional: ferramentas de diagnóstico e de gestão (pp.215-248). Porto Alegre: Artmed.

Borges, L. O., Tamayo, A., \& Alves-Filho, A. (2005). Significado do trabalho entre os profissionais de saúde. In L. O. Borges (Org.), Os profissionais de saúde e seu trabalho (pp.143-197). São Paulo: Casa do Psicólogo.

Bruyne, P., Herman, J., \& Schoutheete, M. (1977). Os modos de investigação. In P. Bruyne, J. Herman \& M. Schoutheete (Orgs.), Dinâmica da pesquisa em ciências sociais (pp.221-251). Rio de Janeiro: F. Alves.

Canguilhem, G. (1995). O normal e o patológico. Rio de Janeiro: Forense Universitária.
Chaves, S. S. S. (2003). Valores como preditores do bem-estar subjetivo. Dissertação de mestrado não-publicada, Programa de Pós Graduação em Psicologia, Universidade Federal da Paraíba, João Pessoa.

Chaves, S. S. S. (2007). O bem-estar subjetivo e os valores humanos em músicos eadvogados da cidade de João Pessoa. Tese de doutorado não-publicada, Programa de Pós-Graduação em Psicologia, Universidade Federal do Rio Grande do Norte, Natal.

Diener, E., \& Emmons, R. A. (1984). The independence of positive and negative affect. Journal of Personality and Social Psychology, 47 (5), 1105-1117.

Garrido, A. (2006). El trabajo: presente y futuro. In A. Garrido (Org.), Sociopsicología del trabajo (pp.19-55). Barcelona: UOC.

Goldberg, D. (1972). The detection of psychiatric illness by questionnaire. London: Oxford University Press.

Gil, A. C. (1987). Métodos e técnicas de pesquisa social. São Paulo: Atlas.

Hutz, C. (2002). Questionário de auto-estima de Rosenberg: adaptação brasileira. Laboratório de Psicometria da UFRGS. Recuperado em 12, 2005, disponível em <www. psicologia.ufrgs.br/laboratorio/>.

Jahoda, M. (1987). Empleo y desempleo: un análisis sociopsicológico. Madrid: Ediciones Morata.

Kohn, M. L., \& Schooler, C. (1983). Work and personality. New Jersey: Ablex Publishing Corporation.

Locke, E. A., \& Taylor, M. S. (1990). Stress, coping, and meaning of work. In A. P. Brief \&W. R. Nord (Org.), Meaning of occupational work (pp.135-170). Massachussets: Lexington Books.

Mendes, A. M., \& Cruz, R. M. (2004). Trabalho e saúde no contexto organizacional: vicissitudes teóricas. In A. Tamayo (Org.), Cultura e saúde nas organizações (pp. 39-55). Porto alegre: Artmed.

Ogden, J. (1999). Psicologia da saúde. Lisboa: Climepsi.

Petrobrás/Federação Única dos Petroleiros (2005). Acordo coletivo de trabalho. Natal.

Rocha, A. P. B. (2005). Expansão urbana de Mossoró (período de 1980 a 2004): geografia dinâmica e reestruturação do território. Natal: EDUFRN.

Rosenberg, M. (1999). Society and the adolescent self-image. Princeton: Princeton University Press. (Originally published in 1965).

Warr, P. (1987). Work, unemployment, mental health. New York: Oxford University Press.

World Health Organization. (1948). Constitution of World Health Organization. Retrieved in 6, 2007, from <http:// www.who.int/about/es>.

Recebido em: 1/9/2009

Versão final reapresentada em: 16/9/2010

Aprovado em: 11/3/2011 
